\title{
Mo2Ga2C: a new ternary nanolaminated carbide
}

C. Hu, Chung-Chuan Lai, Quanzheng Tao, Jun Lu, Joseph Halim, L. Sun, J. Zhang, J. Yang,

B. Anasori, J. Wang, Y. Sakka, Lars Hultman, Per Eklund,

Johanna Rosén and Michel Barsoum

\section{Linköping University Post Print}

\section{Tweet}

N.B.: When citing this work, cite the original article.

Original Publication:

C. Hu, Chung-Chuan Lai, Quanzheng Tao, Jun Lu, Joseph Halim, L. Sun, J. Zhang, J. Yang, B. Anasori, J. Wang, Y. Sakka, Lars Hultman, Per Eklund, Johanna Rosén and Michel Barsoum, Mo2Ga2C: a new ternary nanolaminated carbide, 2015, Chemical Communications, (51), 30, 6560-6563.

http://dx.doi.org/10.1039/c5cc00980d

Copyright: Royal Society of Chemistry http://www.rsc.org/

Postprint available at: Linköping University Electronic Press http://urn.kb.se/resolve?urn=urn:nbn:se:liu:diva-117813 


\title{
$\mathrm{Mo}_{2} \mathrm{Ga}_{2} \mathrm{C}$ : A New Ternary Nanolaminated Carbide
}

C. Hu, ${ }^{\not a}$ C.-C. Lai,${ }^{\not b}$ Q. Tao, ${ }^{\not b}$ J. Lu, ${ }^{b}$ J. Halim,${ }^{a b}$ L. Sun,${ }^{c}$ J. Zhang, ${ }^{c}$ J. Yang, ${ }^{a}$ B. Anasori, ${ }^{a}$ J. Wang, ${ }^{c}$ Y. Sakka, ${ }^{d}$ L. Hultman, ${ }^{b}$ P. Eklund,${ }^{b}$ J. Rosen ${ }^{* b}$ and M. W. Barsoum ${ }^{*} a b$

a Department of Materials Science and Engineering, Drexel University, PA 19104, USA.

${ }^{b}$ Department of Physics, Chemistry, and Biology (IFM), Linköping University, Linköping SE-58183, Sweden.

${ }^{c}$ Institute of Metal Research, Chinese Academy of Sciences, Shenyang 110016, China

${ }^{d}$ Advanced Materials Processing Unit, National Institute for Materials Science, Tsukuba, Ibaraki 305-0047, Japan

\$Contributed equally to this work.

* Corresponding authors: Michel W. Barsoum (barsoumw@drexel.edu) and J. Rosen (johro@ifm.liu.se)

\begin{abstract}
We report the discovery of a new hexagonal $\mathrm{Mo}_{2} \mathrm{Ga}_{2} \mathrm{C}$ phase, wherein two Ga layers instead of one - are stacked in a simple hexagonal arrangement in between $\mathrm{Mo}_{2} \mathrm{C}$ layers. It is reasonable to assume this compound is the first of a larger family.
\end{abstract}

\section{Introduction}

The ternary $\mathrm{M}_{n+1} \mathrm{AX} n$, or MAX, phases (where $\mathrm{M}$ is an early transition metal, $\mathrm{A}$ is an $\mathrm{A}$ group element mostly groups 13 and $14, \mathrm{X}$ is $\mathrm{C}$ and/or $\mathrm{N}$, and $n=1$ to 3), phases are a large family, $70+$, of nanolayered, machinable solids. ${ }^{1-3}$ There are approximately $50 \mathrm{M}_{2} \mathrm{AX}$, or 211 , phases, five $\mathrm{M}_{3} \mathrm{AX}$, or 312, phases and a growing number of $\mathrm{M}_{4} \mathrm{AX}_{3}$, of 413 , phases since that structure was first established in $\mathrm{Ti}_{3} \mathrm{AlN}_{4}$. In all cases, the $\mathrm{M}_{n+1} \mathrm{AX} \mathrm{X}_{n}$ unit cells are hexagonal - space group $\mathrm{P}_{3} / \mathrm{mmc}$ - with two formula units per unit cell. In these compounds, near close-packed $\mathrm{M}$ atoms are interleaved with a single layer of pure A-element; the $\mathrm{X}$ atoms occupy the octahedral sites in between the M atoms. In the 211's, every third layer is an A-group element, in the 312's every fourth layer, and in the 413's every fifth. Recently, these solids have attracted much attention due to their unusual and sometimes unique combination of properties.

Of special interest to this work is the first, and sole, Mo-containing MAX phase, $\mathrm{Mo}_{2} \mathrm{GaC}$, first synthesized in 1967 by reacting Mo and C powders with liquid Ga for four weeks at $850{ }^{\circ} \mathrm{C}$ in an evacuated quartz capsule. ${ }^{4}$ Superconducting behavior below $7 \mathrm{~K}$ has been reported. ${ }^{4,5}$ More recently a theoretical paper was published, predicting some of its properties. ${ }^{6}$ Compared to $\mathrm{Nb}_{2} \mathrm{GaC}$ and $\mathrm{V}_{2} \mathrm{GaC}, \mathrm{Mo}_{2} \mathrm{GaC}$ was predicted to have the highest bulk and lowest shear modulus.

In efforts to synthesize $\mathrm{Mo}_{2} \mathrm{GaC}$, an XRD peak around $9^{\circ} 2 \theta$ suggested the possible existence of $\mathrm{Mo}_{3} \mathrm{GaC}_{2}$. However, since the latter is predicted to be highly unstable, ${ }^{5}$ further work described herein, led us to the discovery of a new phase: $\mathrm{Mo}_{2} \mathrm{Ga}_{2} \mathrm{C}$, wherein two Ga layers instead of one in $\mathrm{Mo}_{2} \mathrm{GaC}$ and all other MAX phases - are stacked in a simple hexagonal arrangement in between $\mathrm{Mo}_{2} \mathrm{C}$ layers. 
The processing details can be found in the ESI. $\dagger$ In short, the new phase was produced in two forms: thin film and bulk. The thin films were grown by direct current magnetron sputtering of elemental targets on $\mathrm{MgO}(111)$ substrates. Bulk $\mathrm{Mo}_{2} \mathrm{Ga}_{2} \mathrm{C}$ samples were synthesized by first heating a $2: 1$ molar ratio of Mo:C powders in flowing Ar at $1000{ }^{\circ} \mathrm{C}$ for $12 \mathrm{~h}$. The resulting, lightly sintered, $\mathrm{Mo}_{2} \mathrm{C}$ compact was crushed into a powder and mixed with $\mathrm{Ga}$ in a $1: 8$ molar ratio. First, the $\mathrm{Ga}$ was heated to $45^{\circ} \mathrm{C}$ to melt it and the $\mathrm{Mo} 2 \mathrm{C}$ powder was homogeneously mixed into the melt in a mortar and pestle, before the mixture was allowed to solidify. The mixture was then placed in a quartz tube that was evacuated using a mechanical pump and sealed. Then, the quartz tube was placed in an alumina furnace and heated at a rate of $10{ }^{\circ} \mathrm{C}$ $\min ^{-1}$ to $850{ }^{\circ} \mathrm{C}$, and held at that temperature for $48 \mathrm{~h}$. After furnace cooling, the powder was immersed in a $37 \mathrm{wt} \% \mathrm{HCl}$ for 3 days to dissolve any residual $\mathrm{Ga}$ and $\mathrm{Ga}_{2} \mathrm{O}_{3}$, if present. A predominantly single phase powder, with $18 \mathrm{wt} \% \mathrm{Mo}_{2} \mathrm{C}$, was obtained after separating the solution and washing the powders several times using deionized water and dried in air.

The morphologies of all the phases resulting from the bulk form were imaged in a scanning electron microscope (SEM) (Supra 50VP, Carl Zeiss AG, Germany) equipped with an energy dispersive spectroscope (EDS). X-ray diffraction, XRD, of the resulting powders was carried using a diffractometer (see the ESI $\uparrow$ for details). High resolution scanning electron microscopy (HRSTEM) and X-ray energy dispersive spectroscopy (EDX) were performed with a double $\mathrm{C}_{\mathrm{s}}$ corrected FEI Titan3 60-300 operated at $300 \mathrm{kV}$, equipped with the Super-X EDX system. Selected area electron diffraction (SAED) characterization was carried out using a FEI Tecnai G2 TF20 UT instrument operated at $200 \mathrm{kV}$, with a point resolution of $0.19 \mathrm{~nm}$.

Fig. 1 shows a $\theta-2 \theta$ XRD pattern of a thin film sample, where the two peaks with highest intensities at $2 \theta=36.97^{\circ}$ and $78.64^{\circ}$ can be assigned to the (111) and (222) diffractions, respectively, of the $\mathrm{MgO}$ substrate. The other nine peaks originate from phases in the thin film with a $d$ spacing with a least common multiple of $\sim 9.04 \AA$. The insets in Fig. 1, shows two XRD pole figures of the thin film sample acquired respectively at constant $2 \theta=34.26^{\circ}$ (inset (i) in Fig. 1) and $62.50^{\circ}$ (inset (ii) in Fig. 1). At $2 \theta=34.26^{\circ}$, six poles can be seen at $\Psi=87-90^{\circ}$ with $60^{\circ}$ separations in between, which shows a six-fold symmetry in the in-plane directions with respect to the sample surface. This symmetry can be assigned to a phase from the film with an in-plane $d$ spacing of $\sim 2.62 \AA$. At $2 \theta=62.50^{\circ}$, three poles can be seen at $\Psi=33-39^{\circ}$ with $120^{\circ}$ separations in between, while two groups of six poles with $60^{\circ}$ separations in between are observed at $\Psi=81^{\circ}$ and $\Psi=87-90^{\circ}$, respectively. The poles at $\Psi=33-39^{\circ}$ and $87-90^{\circ}$ are assigned to $\mathrm{MgO}\{220\}$ from the $\mathrm{MgO}(111)$ substrate, which has a three-fold rotational axis along $\mathrm{MgO}[111]$. The six-fold symmetric poles at $\Psi=81^{\circ}$ can be assigned to a phase oriented in accordance with the in-plane orientation of the substrate, i.e. it is epitaxially grown on the $\mathrm{MgO}$ substrate.

\footnotetext{
${ }^{\dagger}$ Electronic supplementary information (ESI) available: Synthesis of materials, and characterization techniques. See DOI: $10.1039 / c 5 c c 00980 d$
} 


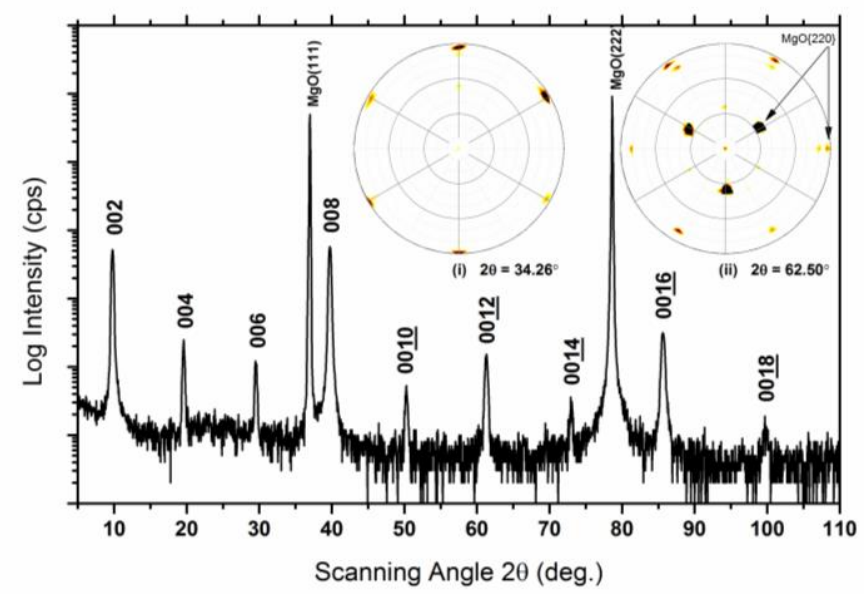

Fig. 1 XRD pattern of $\mathrm{Mo}_{2} \mathrm{Ga}_{2} \mathrm{C}$ thin film sample. The two peaks with highest intensities at $2 \theta=36.97^{\circ}$ and $78.64^{\circ}$ are those of the $\mathrm{MgO}$ substrate. The other 9 peaks come from the thin film and represent a series of interplanar spacing $d$ with a least common multiple of $\sim 9.04 \AA$. The pole figure labelled (i) was acquired at a constant $2 \theta=34.26^{\circ}-$ and the one labelled (ii) was acquired at $2 \theta=62.50^{\circ}$.

Fig. $2 \mathrm{a}$ and $\mathrm{b}$ are SAED patterns from the new compound. The phase has a hexagonal structure with $a$ and $c$ lattice parameters of $3.05 \AA$ and $18.19 \AA$, respectively. The possibility that those patterns originate from a $312 \mathrm{MAX}$ structure (i.e., the hypothetical $\mathrm{Mo}_{3} \mathrm{GaC}_{2}$ which is not stable $^{5}$ ) can be excluded for the following reasons. As noted above, the chemical composition analysis shown in Fig. 2c exhibits a different $\mathrm{Mo} / \mathrm{Ga}$ ratio from that of a $\mathrm{Mo}_{3} \mathrm{GaC}_{2}$ phase. The structure is also not that of $\mathrm{Ta}_{2} \mathrm{~S}_{2} \mathrm{C}$ and $\mathrm{Nb}_{2} \mathrm{~S}_{2} \mathrm{C}$ phases, which have the same, ${ }^{7,8}$ or at least similar " 221 " stoichiometries, since they belong to the space group $\boldsymbol{R} \overline{\mathbf{3}} \boldsymbol{m} \mathbf{1}$. Furthermore the stacking observed in HRSTEM (below), is inconsistent with either of these sulphides or a 312 MAX phase. 

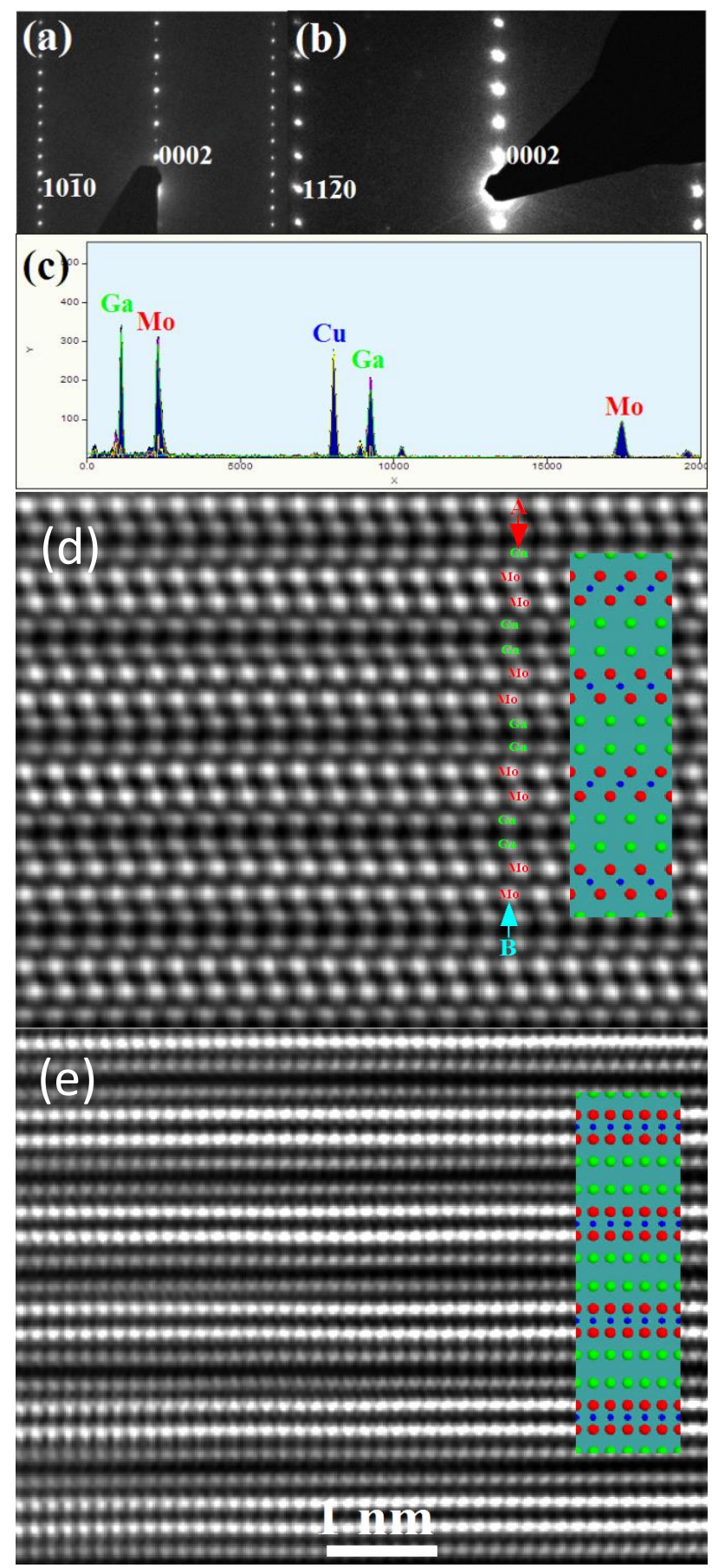

Fig. 2 (a) Selected area electron diffraction of Mo2Ga2C thin films in $[11 \overline{2} 0]$ and, (b) $[10 \overline{1} 0]$ zone axes, (c) EDS spectrum; (d) HAADF images in the (d) $[11 \overline{2} 0]$ and, (e) $[10 \overline{1} 0]$ zone axes. Insets are corresponding atomic structure models indicating the corresponding positions of the $\mathrm{Ga}$ and Mo atoms in the stacking sequence.

To reveal the detailed structure, a $Z$ contrast image was obtained using HRSTEM. Fig. 2c and $\mathrm{d}$ show the HRSTEM images with the beam aligned along the $[\mathbf{1 1} \overline{\mathbf{2}} \mathbf{0}]$ and $[\mathbf{1 0} \overline{\mathbf{1}} \mathbf{0}]$ zone axes, respectively. The $Z$ contrast images show a double-layer structural feature. The bright and dark spots should correspond to the Mo and Ga atoms, respectively.

The corresponding EDX maps shown in Fig. 3(a-f) confirm the Mo-Mo-Ga-Ga-Mo-Mo layering. The simplest description of the structure is the following: start with a $211 \mathrm{MAX}$ phase 
structure and simply insert one extra Ga layer on top of the existing Ga. Surprisingly, the two Ga layer lie exactly on top of each other (i.e. not close-packed), an unusual arrangement indeed.

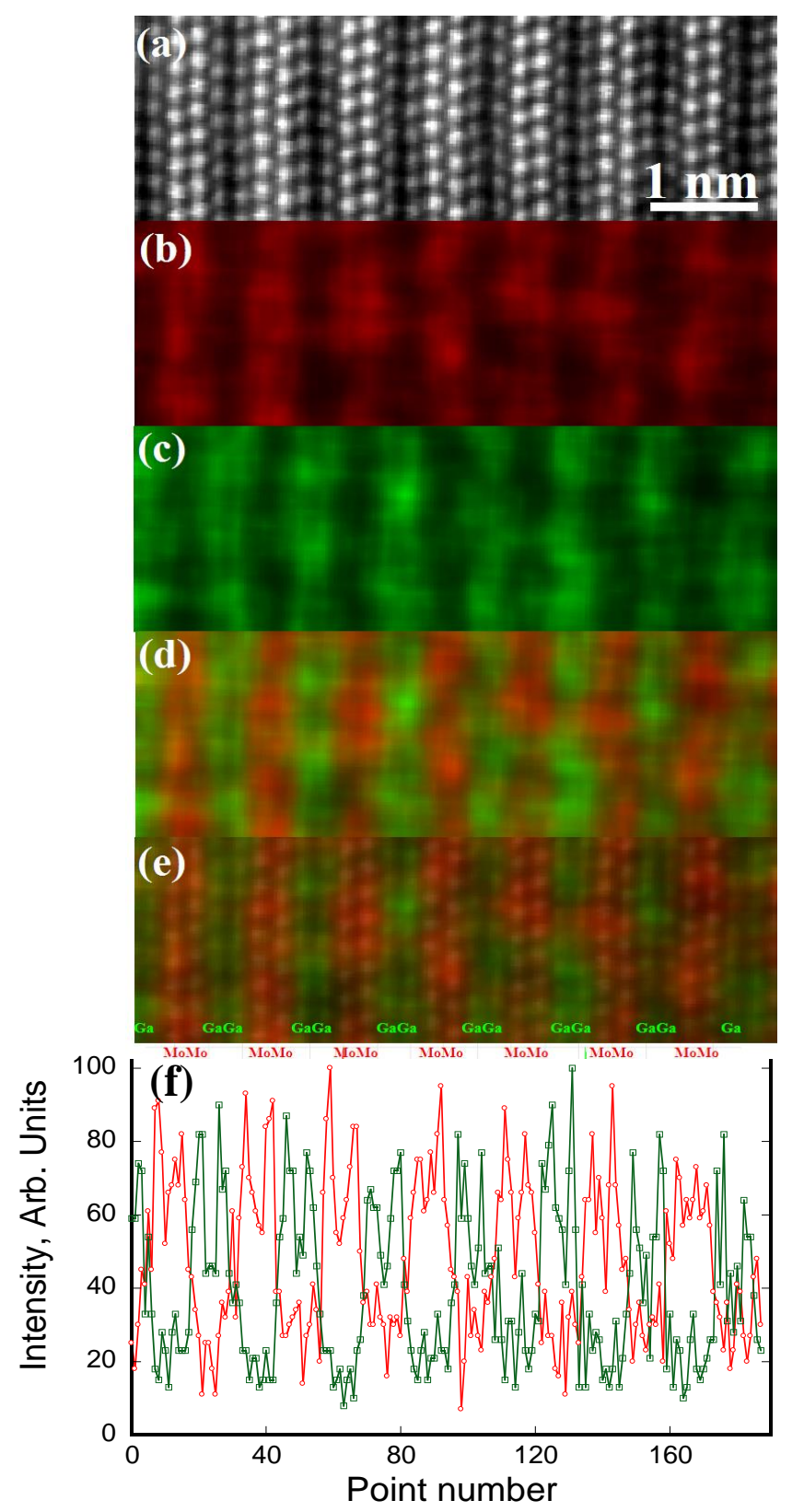

Fig. 3 (a) HAADF image and corresponding, (b) Mo, (c) Ga, and, (d) Mo and Ga maps, (e) HAADF image superimposed with Mo and Ga maps, (f) line scan along [0001] direction a $\mathrm{Moz}_{2} \mathrm{Ga}_{2} \mathrm{C}$ film.

Based on the Z-contrast images, the distance between adjacent Mo layers was estimated to be $2.27 \AA$. The separation between the Mo and Ga layers is shortest: $2.09 \AA$. The separation between the adjacent Ga layers at $2.64 \AA$ is relatively high. Based on the measured data, initial atomic positions of the Mo and Ga atoms are found and used as input data to the Rietveld refinement below.

Fig. 4 shows a typical XRD pattern of the phase obtained after dissolving the unreacted Ga from the bulk sample. When this new phase was imaged in a HRSTEM (see above) its structure was found to be unlike any other MAX phase known, in that there were two Ga layers separating 
the $\mathrm{Mo}_{2} \mathrm{C}$ blocks. Making use of this insight, the XRD pattern was analyzed assuming the unit cell shown in the inset of Fig. 4.

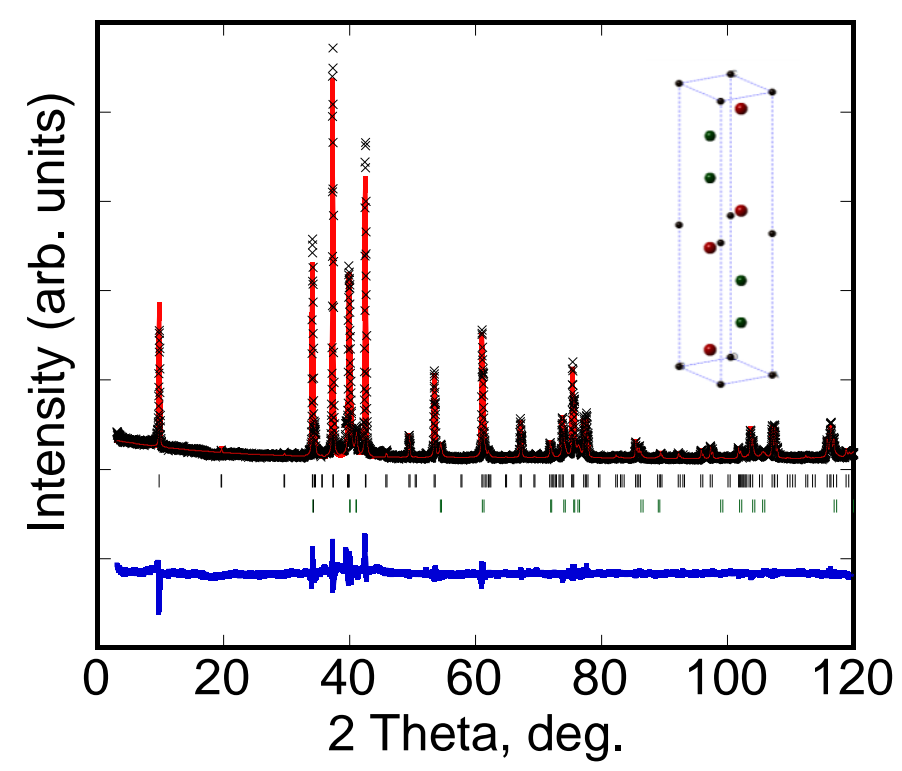

Fig. 4 Powder XRD patterns indexed to Mo2Ga2C showing observed pattern (black crosses), Rietveld generated pattern (red line) and difference between the two (blue line). The black and green ticks below the pattern represent the peak positions of $\mathrm{Mo}_{2} \mathrm{Ga}_{2} \mathrm{C}$ phase, and $\mathrm{Mo}_{2} \mathrm{C}$ phase, respectively. The $\chi^{2}$ value was 4.93. Inset shows schematic of a unit cell where the $\mathrm{Ga}$ atoms are green, $\mathrm{Mo}$ are red and carbon are black.

To determine the composition of this new phase, elastic recoil detection analysis (ERDA) was carried out on a close to phase-pure thin film sample containing traces of Mo-C intermetallic phases, and the Mo, $\mathrm{Ga}$ and $\mathrm{C}$ contents, in at\%, were found to be, respectively, $38.9 \%, 42.5 \%$, $18.3 \%$, with a trace amount of oxygen $(0.34$ at\%). This composition is consistent with $2: 2: 1$, within the error margins of the technique.

The results of the Rietveld analysis are summarized in Table 1. The space group assumed was that of the MAX phases: $P 6_{3} / m m c$. The $a$ and $c$-lattice parameters were calculated to be 3.03396(4) $\AA$ and 18.0814(3) $\AA$, respectively. The overall temperature factor was calculated to be $0.22(3) \AA^{2}$ and $6.5(6) \%$ of the sample was preferably oriented in the (001) direction. The presence of 19.8(4) wt $\%$ of $\mathrm{Mo}_{2} \mathrm{C}$ was also found. When this phase was taken into account, the $\chi^{2}$ value was 4.93 . The occupancies for all atoms were fixed at $100 \%$.

Table 1 Atomic positions in $\mathrm{Mo}_{2} \mathrm{Ga}_{2} \mathrm{C}$ determined from the Rietveld analysis of the XRD pattern shown in Fig. 1. The space group was $P 6_{3} / m m c$. The $a$ and $c$-lattice parameters were calculated to be $3.03396(4) \AA$ and $18.0814(3) \AA$, respectively.

\begin{tabular}{|l|l|l|l|l|}
\hline Element & $x$ & $y$ & $z$ & Wyckoff positions \\
\hline Mo & $1 / 3$ & $2 / 3$ & $0.06571(11)$ & $4 \mathrm{f}$ \\
\hline Ga & $1 / 3$ & $2 / 3$ & $0.68247(13)$ & $4 \mathrm{f}$ \\
\hline C & 0 & 0 & 0 & $2 \mathrm{a}$ \\
\hline
\end{tabular}


A list of the $h k l$ indices of the various peaks - theoretical and experimentally observed - and their intensities and d spacings are listed in Table S1 (ESI $\dagger$ ), which shows generally good agreement between the theory and experiment. It should be noted here that since the simple hexagonal arrangement of the Ga atoms is somewhat unusual, other arrangements were tested, where the Ga layers were sheared with respect to each other. The $\chi^{2}$ values in those cases were significantly higher than for the unit cell shown in the inset of Fig. 4.

The importance of this work lies beyond the discovery of a totally new phase, as exciting as that may be. After Kudielka and Rohde, ${ }^{9}$ discovered the first MAX phase - then referred to as a H phase - in 1960, Nowotny and co-workers discovered over 50 such phases, including the 312 phases. ${ }^{10}$ In 1999 Ti$_{4} \mathrm{AlN}_{3}$ - the first 413 phase - was discovered; ${ }^{11}$ since then over five 413 phases have been discovered, not including solid solutions. Based on this track record, it is quite reasonable to assume that $\mathrm{Mo}_{2} \mathrm{Ga}_{2} \mathrm{C}$ is the first of a new and distinct family of MAXrelated phases.

\section{Acknowledgments}

We acknowledge support from the Swedish Research Council (project grants \#621-2011-4420, 642-2013-8020, and 621-2014-4890), the Swedish Foundation for Strategic Research through the Synergy Grant FUNCASE Functional Carbides for Advanced Surface Engineering (C.-C. L., J. R., P. E., M. W. B., J. H.), the Future Research Leaders 5 Program (P. E., J. L.), and the ERC Grant agreement [no. 258509] (J. R.). The Knut and Alice Wallenberg Foundation supported the Electron Microscopy Laboratory at Linköping University operated by the Thin Film Physics Division. The support from Ningbo Natural Science Foundation (2013A610128) and National Natural Science Foundation of China (U1232136) is also acknowledged.

\section{References}

1. M. W. Barsoum, MAX Phases: Properties of Machinable Carbides and Nitrides, Wiley VCH GmbH \& Co., Weinheim, 2013.

2. P. Eklund, M. Beckers, U. Jansson, H. Högberg and L. Hultman, Thin Solid Films, 2010, 518 1851-1878.

3. Z.-M. Sun, International Materials Reviews, 2011, 56, 143-166.

4. L. Toth, J. Less Comm. Met., 1967, 13 129 131.

5. R. Meshkian, A. S. Ingason, M. Dahlqvist, A. Petruhins, U. B. Arnalds, F. Magnus, J. Lu and J. Rosen, Sub for pub.

6. I. R. Shein and A. L. Ivanovskii, Physica C, 2010, 470, 533-537.

7. R. P. Ziebarth, J. K. Vassiliou and F. J. Disalvo, J. Less Comm. Met., 1989, 156, 207-211.

8. O. Beckmann, H. Boller and H. Nowotny, Monatsh. Chem., 1970, 101, 945955.

9. H. Kudielka and H. Rohde, Z. Kristalogr., 1960, 114, 447.

10. H. Nowotny, Prog. Solid State Chem., 1970, 2, 27-70.

11. M. W. Barsoum, L. Farber, I. Levin, A. Procopio, T. El-Raghy and A. Berner, J. Amer. Cer. Soc., 1999, 82, 2545-2547. 


\section{Supplementary Information for}

\section{$\mathrm{Mo}_{2} \mathrm{Ga}_{2} \mathrm{C}$ : A New Ternary Nanolaminated Carbide}

C. Hu, ${ }^{\not a}$ C.-C. Lai, ${ }^{\not b}$ Q. Tao,${ }^{\not b}$ J. Lu, ${ }^{b}$ J. Halim, ${ }^{a b}$ L. Sun, ${ }^{c}$ J. Zhang,${ }^{c}$ J. Yang, ${ }^{a}$ B. Anasori, ${ }^{a}$ J. Wang, ${ }^{c}$ Y. Sakka, ${ }^{d}$ L. Hultman, ${ }^{b}$ P. Eklund, ${ }^{b}$ J. Rosen ${ }^{* b}$ and M. W. Barsoum ${ }^{*}{ }^{a b}$

${ }^{a}$ Department of Materials Science and Engineering, Drexel University, PA 19104, USA.

${ }^{b}$ Department of Physics, Chemistry, and Biology (IFM), Linköping University, Linköping SE-58183, Sweden.

${ }^{c}$ Institute of Metal Research, Chinese Academy of Sciences, Shenyang 110016, China

${ }^{d}$ Advanced Materials Processing Unit, National Institute for Materials Science, Tsukuba, Ibaraki 305-0047, Japan

* Contributed equally to this work.

*Corresponding authors: Michel W. Barsoum (barsoumw@drexel.edu) and J. Rosen (johro@ifm.liu.se)

\section{S1 Experimental Details:}

a) Synthesis of the bulk $\mathrm{Mo}_{2} \mathrm{Ga}_{2} \mathrm{C}$ :

The starting materials used were commercial Mo (63 NS, Metco Inc., Anderson, SC), graphite (Grade 4827, Asbury Graphite Mills Inc., Asbury, NJ) powders and Ga shots (99.99\%) (Roto Metals Inc., San Leandro, CA). First the Mo and graphite powders were weighed in a 2:1 molar ratio and placed in a plastic bottle and mixed for $24 \mathrm{~h}$ using agate balls as the milling media. The resulting, lightly sintered, $\mathrm{Mo}_{2} \mathrm{C}$ compact was crushed into powder and mixed with $\mathrm{Ga}$ in a 1:8 molar ratio to form $\mathrm{Mo}_{2} \mathrm{Ga}_{2} \mathrm{C}$. The mixture was then placed in a quartz tube that was evacuated using a mechanical vacuum pump and sealed. The quartz tube was then placed in an alumina tube furnace and heated at a rate of $10{ }^{\circ} \mathrm{C} / \mathrm{min}$ to $850{ }^{\circ} \mathrm{C}$, and held at that temperature for $48 \mathrm{~h}$. After furnace cooling, the powder was immersed in a $37 \mathrm{wt} . \% \mathrm{HCl}$ solution for 3 days to dissolve any residual $\mathrm{Ga}$ and $\mathrm{Ga}_{2} \mathrm{O}_{3}$ if present. Predominantly single phase $\mathrm{Mo}_{2} \mathrm{Ga}_{2} \mathrm{C}$ powder - with $\approx 20$ wt. $\%$ $\mathrm{Mo}_{2} \mathrm{C}$ - was obtained. The powders were then washed with deionized water several times and dried in air for further analysis.

b) Thin film synthesis:

Direct current magnetron sputtering was used to grow Mo-Ga-C thin films were synthesized. The films were co-deposited from three elemental targets, Mo (3-inch, 99.95\% purity, SCOTECH Ltd.), Ga (2-inch, $99.99999 \%$ purity, 5N Plus UK Ltd.) and C (3-inch, 99.99\% purity, SCOTECH Ltd.) with respective powers $40 \mathrm{~W}, 18 \mathrm{~W}$ and $200 \mathrm{~W}$ and at $\sim 0.5 \mathrm{~Pa}$ Ar with a background pressure in the range of $10^{-7} \mathrm{~Pa}$. Due to its low melting point $\left(\sim 30^{\circ} \mathrm{C}\right)$, the $\mathrm{Ga}$ source was kept in a concave stainless steel crucible right below the substrate, in line with previously developed procedures. [A. Petruhins, A. S. Ingason, M. Dahlqvist, A. Mockute, M. Junaid, J. Birch, J. Lu, L. Hultman, P. O. Å. Persson and J. Rosen, Phys. Status Solidi RRL, vol. 7, no. 11, pp. 971-974, 2013]. The Mo and $\mathrm{C}$ targets were tilted $+35^{\circ}$ and $-35^{\circ}$ away from the horizontal position of the Ga target, co-focusing onto the rotating substrate. 
The thin films were grown on $\mathrm{MgO}(111)$ substrates $\left(10 \times 10 \times 0.5 \mathrm{~mm}^{3}\right.$, Latech Ltd.) that were ultrasonically cleaned sequentially in acetone, ethanol and isopropanol for 10 minutes at each stage. Before deposition, the substrate was heated to $560^{\circ} \mathrm{C}$ at the base pressure, followed by a 10 minutes pre-sputtering with the same powers for deposition. A shutter was inserted to blind the substrate from the target's line-of-sight when pre-sputtering, and was afterwards removed directly to start the deposition at the same substrate temperature set-point $\left(560^{\circ} \mathrm{C}\right)$.

\section{S2 Characterization Details:}

a) Details of XRD Experimental Parameters and Refinement Conditions

XRD patterns were obtained with a diffractometer (Rikagu Smartlab, Tokyo, Japan), with a step size of $0.02^{\circ}$ in the $3^{\circ}-120^{\circ} 2 \theta$ range with a step time of $7 \mathrm{~s}$ with a $10 \times 10 \mathrm{~mm}^{2}$ window slit. Scans were made with $\mathrm{Cu} \mathrm{K}_{\alpha}$ radiation $(40 \mathrm{kV}$ and $44 \mathrm{~mA}$ ).

Rietveld refinement of the XRD diffractograms was carried out using the FULLPROF code [J. Rodriguez-Carvajal, Phys. B 192 (1993) 55-69]. The refinement was carried out from $8.5^{\circ}$ to $120^{\circ}$ $2 \theta$. Refined parameters were: five background parameters, scale factors from which relative phase fractions are evaluated, $Y$ profile parameter for peak width, lattice parameters (LPs), the overall thermal factor, preferred orientation and atomic positions for all phases. The experimental and those calculated from the Rietveld refinement are summarized in Table S1.

Table S1: X-ray $(\mathrm{Cu} \mathrm{K} \alpha)$ powder diffraction data for $\mathrm{Mo}_{2} \mathrm{Ga}_{2} \mathrm{C}$.

\begin{tabular}{|cccccccc|}
\hline $\begin{array}{c}\text { Peak } \\
\text { Number }\end{array}$ & $\boldsymbol{h}$ & $\boldsymbol{k}$ & $\boldsymbol{l}$ & $\mathbf{2 \theta}$ & $\begin{array}{c}\boldsymbol{I} \\
\text { calculated }\end{array}$ & $\begin{array}{c}\boldsymbol{I} \\
\text { observed }\end{array}$ & $\boldsymbol{d}_{\boldsymbol{h} \boldsymbol{l} \text { }}$ \\
\hline 1 & 0 & 0 & 2 & 9.775 & 440.1 & 460.1 & 9.040678 \\
\hline 2 & 0 & 0 & 4 & 19.623 & 12.9 & 0 & 4.520339 \\
\hline 3 & 0 & 0 & 6 & 29.619 & 8.7 & 0 & 3.013559 \\
\hline 4 & 1 & 0 & 0 & 34.095 & 639.6 & 646.7 & 2.627484 \\
\hline 5 & 1 & 0 & 1 & 34.465 & 87.6 & 79.1 & 2.600175 \\
\hline 6 & 1 & 0 & 2 & 35.552 & 4.6 & 15.7 & 2.523087 \\
\hline 7 & 1 & 0 & 3 & 37.303 & 1439.2 & 1607.4 & 2.408563 \\
\hline 8 & 1 & 0 & 4 & 39.644 & 22.3 & 31.1 & 2.271614 \\
\hline 9 & 0 & 0 & 8 & 39.853 & 480.5 & 513.7 & 2.26017 \\
\hline 10 & 1 & 0 & 5 & 42.493 & 1128.4 & 1308.5 & 2.125649 \\
\hline 11 & 1 & 0 & 6 & 45.779 & 16.4 & 83.9 & 1.980435 \\
\hline 12 & 1 & 0 & 7 & 49.44 & 91.9 & 86.8 & 1.842001 \\
\hline 13 & 0 & 0 & 10 & 50.43 & 3.1 & 0 & 1.808136 \\
\hline 14 & 1 & 0 & 8 & 53.43 & 361.3 & 375.3 & 1.713455 \\
\hline 15 & 1 & 0 & 9 & 57.718 & 0.3 & 0 & 1.595959 \\
\hline
\end{tabular}




\begin{tabular}{|c|c|c|c|c|c|c|c|}
\hline $\begin{array}{c}\text { Peak } \\
\text { Number }\end{array}$ & $\boldsymbol{h}$ & $k$ & $l$ & $2 \theta$ & $\begin{array}{c}I \\
\text { calculated }\end{array}$ & $\begin{array}{c}I \\
\text { observed }\end{array}$ & $d_{h k l}$ \\
\hline 16 & 1 & 1 & 0 & 61.032 & 530.3 & 492.5 & 1.516979 \\
\hline 17 & 0 & 0 & 12 & 61.49 & 14.2 & 12.1 & 1.50678 \\
\hline 18 & 1 & 1 & 2 & 61.979 & 20.9 & 20.1 & 1.496064 \\
\hline 19 & 1 & 0 & 10 & 62.282 & 7.1 & 5.8 & 1.489519 \\
\hline 20 & 1 & 1 & 4 & 64.771 & 4.4 & 1.3 & 1.438156 \\
\hline 21 & 1 & 0 & 11 & 67.114 & 174 & 128.1 & 1.393528 \\
\hline 22 & 1 & 1 & 6 & 69.29 & 6.6 & 16.4 & 1.354988 \\
\hline 23 & 2 & 0 & 0 & 71.795 & 68.6 & 56.8 & 1.313742 \\
\hline 24 & 2 & 0 & 1 & 72.014 & 8.5 & 7.2 & 1.310288 \\
\hline 25 & 1 & 0 & 12 & 72.217 & 7.8 & 6.3 & 1.307101 \\
\hline 26 & 2 & 0 & 2 & 72.668 & 1 & 1 & 1.300087 \\
\hline 27 & 0 & 0 & 14 & 73.228 & 2 & 1.6 & 1.291525 \\
\hline 28 & 2 & 0 & 3 & 73.755 & 185.1 & 165.8 & 1.283603 \\
\hline 29 & 2 & 0 & 4 & 75.265 & 2.7 & 2.5 & 1.261544 \\
\hline 30 & 1 & 1 & 8 & 75.404 & 432.9 & 431.9 & 1.259573 \\
\hline 31 & 2 & 0 & 5 & 77.193 & 185.9 & 182.1 & 1.234785 \\
\hline 32 & 1 & 0 & 13 & 77.604 & 181.9 & 193.4 & 1.229266 \\
\hline 33 & 2 & 0 & 6 & 79.529 & 3.4 & 4.6 & 1.204282 \\
\hline 34 & 2 & 0 & 7 & 82.267 & 17.9 & 24.4 & 1.17099 \\
\hline 35 & 1 & 1 & 10 & 83.031 & 5.5 & 9 & 1.162145 \\
\hline 36 & 1 & 0 & 14 & 83.3 & 0.9 & 1.5 & 1.159069 \\
\hline 37 & 2 & 0 & 8 & 85.405 & 90.3 & 89.9 & 1.135807 \\
\hline 38 & 0 & 0 & 16 & 85.942 & 46.6 & 49.1 & 1.130085 \\
\hline 39 & 2 & 0 & 9 & 88.945 & 0.2 & 0.1 & 1.099527 \\
\hline 40 & 1 & 0 & 15 & 89.347 & 26.2 & 18.9 & 1.095625 \\
\hline 41 & 1 & 1 & 12 & 92.199 & 28.2 & 34.5 & 1.069042 \\
\hline 42 & 2 & 0 & 10 & 92.898 & 2.8 & 3.7 & 1.062824 \\
\hline 43 & 1 & 0 & 16 & 95.804 & 48.9 & 45.5 & 1.038136 \\
\hline 44 & 2 & 0 & 11 & 97.284 & 74.5 & 80.4 & 1.026246 \\
\hline 45 & 0 & 0 & 18 & 100.14 & 1.4 & 5.9 & 1.00452 \\
\hline 46 & 2 & 1 & 0 & 101.728 & 63.2 & 69.1 & 0.993096 \\
\hline 47 & 2 & 1 & 1 & 101.941 & 5.5 & 5.8 & 0.991601 \\
\hline 48 & 2 & 0 & 12 & 102.138 & 3.7 & 4.2 & 0.990218 \\
\hline 49 & 2 & 1 & 2 & 102.579 & 1.6 & 2.2 & 0.987158 \\
\hline 50 & 1 & 0 & 17 & 102.762 & 5.5 & 7.5 & 0.985896 \\
\hline 51 & 1 & 1 & 14 & 103.128 & 8.9 & 10 & 0.983394 \\
\hline 52 & 2 & 1 & 3 & 103.647 & 190.3 & 177 & 0.979883 \\
\hline 53 & 2 & 1 & 4 & 105.15 & 2.8 & 2.3 & 0.969963 \\
\hline 54 & 2 & 1 & 5 & 107.098 & 211.4 & 218.3 & 0.957642 \\
\hline 55 & 2 & 0 & 13 & 107.519 & 104.8 & 111.9 & 0.95506 \\
\hline
\end{tabular}




\begin{tabular}{|cccccccc|}
$\begin{array}{c}\text { Peak } \\
\text { Number }\end{array}$ & $\boldsymbol{h}$ & $\boldsymbol{k}$ & $\boldsymbol{l}$ & $\mathbf{2 \theta}$ & $\begin{array}{c}\boldsymbol{I} \\
\text { calculated }\end{array}$ & $\begin{array}{c}\boldsymbol{I} \\
\text { observed }\end{array}$ & $\boldsymbol{d}_{\boldsymbol{h} \boldsymbol{k} \boldsymbol{~}}$ \\
\hline 56 & 2 & 1 & 6 & 109.508 & 5.6 & 16.2 & 0.943201 \\
\hline 57 & 1 & 0 & 18 & 110.362 & 0.8 & 5.4 & 0.938286 \\
\hline 58 & 2 & 1 & 7 & 112.403 & 19.4 & 37 & 0.926948 \\
\hline 59 & 2 & 0 & 14 & 113.517 & 1.1 & 2.6 & 0.921001 \\
\hline 60 & 2 & 1 & 8 & 115.822 & 132.4 & 125.5 & 0.9092 \\
\hline 61 & 1 & 1 & 16 & 109.508 & 5.6 & 16.2 & 0.943201 \\
\hline 62 & 0 & 0 & 20 & 110.362 & 0.8 & 5.4 & 0.938286 \\
\hline 63 & 1 & 0 & 19 & 112.403 & 19.4 & 37 & 0.926948 \\
\hline 64 & 2 & 1 & 9 & 113.517 & 1.1 & 2.6 & 0.921001 \\
\hline
\end{tabular}

b) TEM, XRD and Structural Characterization

The TEM specimens were prepared by mechanic polishing followed by ion thinning down to electron transparency. High resolution scanning electron microscopy (HRSTEM) and X-ray energy dispersive spectroscopy (EDX) were performed with a double $\mathrm{C}_{\text {s }}$ corrected FEI Titan3 60300 operated at $300 \mathrm{kV}$, equipped with the Super-X EDX system. Selected area electron diffraction (SAED) characterization was carried out using a FEI Tecnai G2 TF20 UT instrument operated at $200 \mathrm{kV}$ with a point resolution of $0.19 \mathrm{~nm}$. Structural characterization of the thin films was performed through X-ray diffraction (XRD). The system utilized was a Panalytical Empyrean MRD with a $\mathrm{Cu} \mathrm{K} \mathrm{K}_{\alpha}$ source. The measurements performed were symmetric $(\theta-2 \theta)$ scans obtained by employing a hybrid mirror and a $0.27^{\circ}$ parallel plate collimator in the incident and the diffracted beam side, respectively.

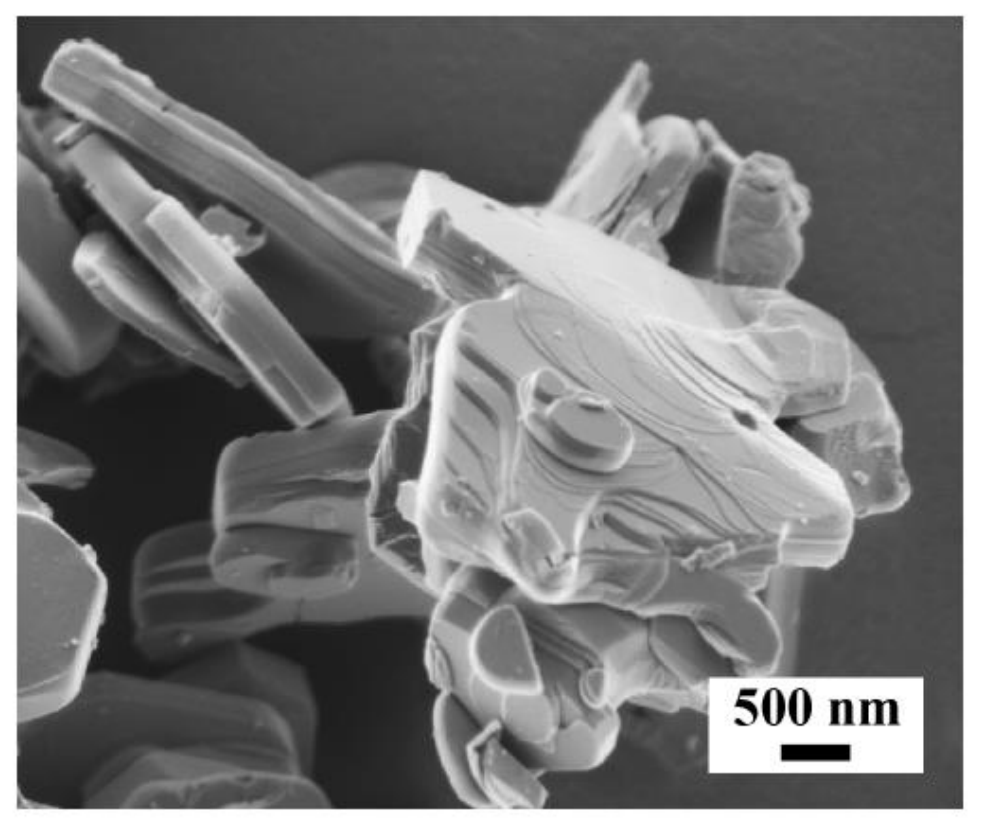

Fig. S1 Scanning electron microscope micrograph of $\mathrm{Mo}_{2} \mathrm{Ga}_{2} \mathrm{C}$ powders showing typical MAX phase platelet morphology. 


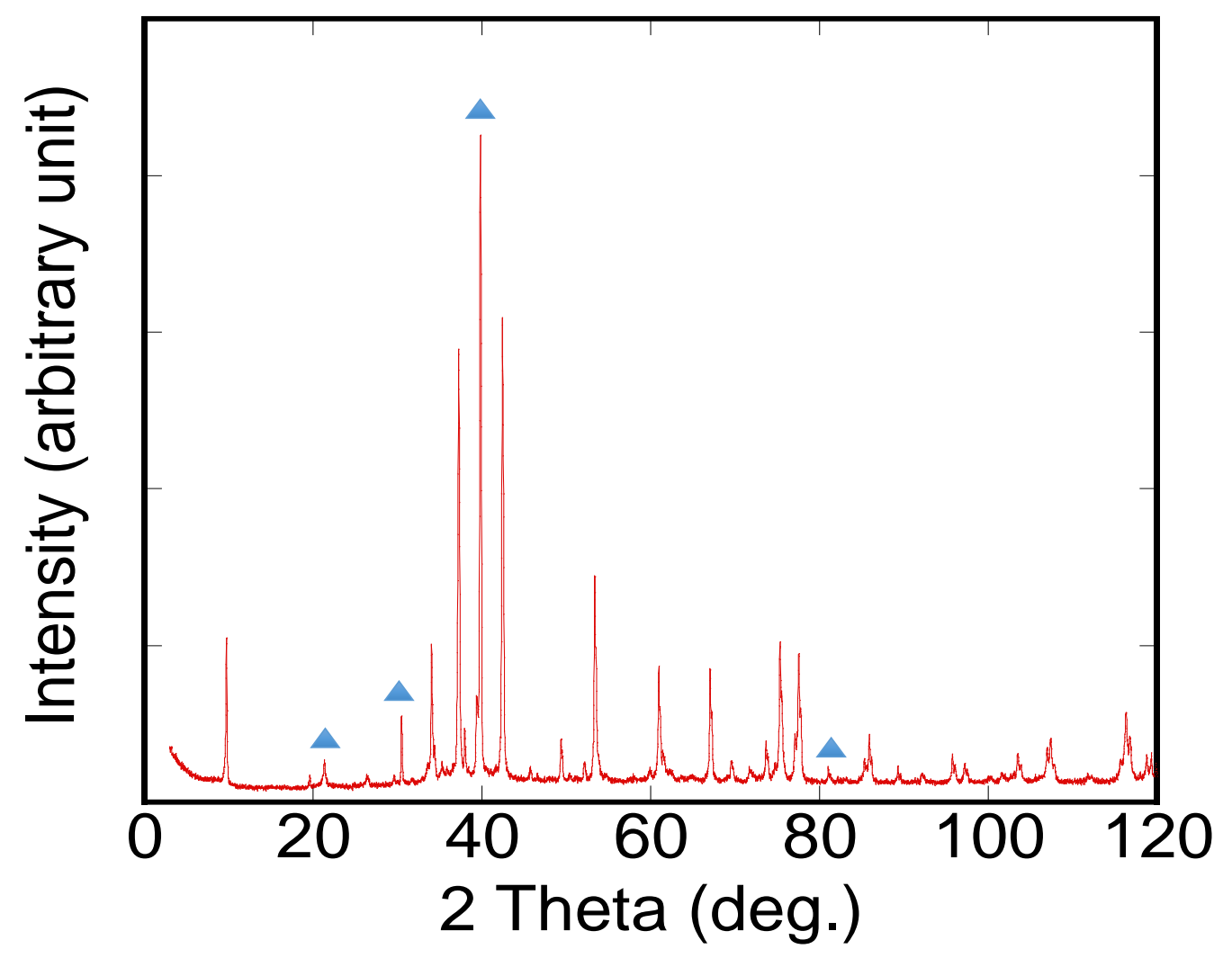

Fig. S2 XRD pattern of Mo2Ga2C bulk sample, the triangle markers represent peaks for free Gallium. 